$\xi=-1$

\title{
The development of simulation model on environmental uncertainty factors for interval project completion
}

\author{
Zirawani Baharum $^{1 *}$, Yuvendra Rao Venkatesan ${ }^{1}$, Syazwa Nabila Mohd Raidzuan', Muhammad Imran Qureshi ${ }^{1}$ \\ ${ }^{1}$ Malaysian Institute of Industrial Technology, Universiti Kuala Lumpur, Jalan Persiaran Sinaran Ilmu, \\ Bandar Seri Alam, 81750 Johor Bahru, Johor, Malaysia \\ *Corresponding author E-mail: zirawani@unikl.edu.my
}

\begin{abstract}
The construction industry has many underlying causes of uncertainty that has impact on late delivery of project completion's performance as well as in time management. The issue on uncertainty delays directly impact the project performance that leads into unnecessary time extension. The objective of the research is the way to create a valid model towards the environmental uncertainty factors. Therefore, this research is conducted to identify the impact of environmental issues which affect the period of project completion using the Witness software system. A literature review revealed the types of other uncertainty factors that affect the project completion by using other software's such as Monte Carlo analysis and relative important index. This research is intended to measure the impact of each environmental factor using the Witness software system by evaluating their significant level of each. The significant level of the factors was determined by using the SPSS statistics software tools. The model will help to manage the time and costing factors by reducing the main impact from the environment. This will aid all project contractors in managing their resources and time utilities.
\end{abstract}

\section{Introduction}

This research was conducted to study about the project delay completion causes by the environmental issues in Malaysia. The main problem was rectified through research on the project delay completion. Nowadays, disaster or acts of god become an unpredictable factor that delays the operation inside the construction industry. This study will mainly focus on the effect of environmental factors that delays the project completion and analyse the significance of each factors against the time of construction completion. The research is done to create a valid model and simulating the model using Witness software system. In fact, the numbers of issues have been increasing in construction sector in terms of completion period. Besides that, contractors plan according to their project procedures and operation stage, thus uncertainty factors give impact in project period that exten(1)ds the time linearly.

\subsection{Background of the Study}

Construction is a large, dynamic, and complex industry sector that plays an important role in the world. Construction workers and employers build our roads, houses, and workplaces, repair and maintain our nation's physical infrastructure. Construction work can involve building of new structures, which may include activities involved with subdividing land for sale as building sites or preparation of sites for new construction. The delay problem in the construction industry is a worldwide phenomenon. Delays occur in most construction projects, either simple or complex. In construction, delay can be defined as the extension of time in the completion of project. In short delay means failure to complete project in targeted time and budgeted cost as agreed in contract. The occurrence of delay is whether concurrently with other delays and all of them can impact the project completion date. According to (2), uncertainty is an inherent part of project management. It is critical for managing large high-risk projects but can also directly affect the bottom line of relatively routine projects. In construction, engineering uncertainty and the concomitant risk lurk everywhere such as uncertain duration, uncertain cost, sudden weather changes, equipment breakdown, human resource problems, unexpected changes in project scope, and others.

\section{Literature Review}

\subsection{A Brief History of Modelling and Simulation Pro- cess}

Modelling is a process of producing a model which represents of the construction and working of the system of interest. The purpose of the model is to enable the analyst to predict the effect of changes to the system. Simulation is the operation of the model represent the real-system. The model can be reconfigured and experimented, (3). However, simulation models have limited applications in construction activities, mainly because of complexities involved in constructing a valid model and the average time required (4). The main use is for processes with repetitive nature at work task level. The right representation of processes requires detailed simulation models with considerable effort that was required to create these simulation models. In addition, the focus generally is on a particular type of work, with the simulation model considering only particular amount of interactions with other work performed on site. Once the simulation characters are defined, they are kept fixed during simulation. Additionally, construction planners are reluctant to base their decisions individually on statistical and chart reports. 


\subsection{Delays in construction}

Delays is a common factor in most construction project and it could be defined as time overrun either beyond completion date specified in contract or lapse the actual date that parties permitted upon for delivery of project, (2). According to (3) studied that the delays and cost overruns in 894 projects from 17 infrastructure sectors. Delays is one of the root causes behind the cost escalation. Larger projects have experienced much high cost overrun compared to smaller ones. According to (5), identified major causes of delays, effects of delays and methods of shorten the delays in construction project in UTM construction project. The most significant group that cause delay was contractor-client related and consultant related. According to (3), construction delay is a complex function in construction project and also one of the biggest problems construction firms face in Libya. In this study, the criteria of contractor's factors that cause delay and given ranking is based on the mean value criteria and in further analysed are identified as the risk of delay in construction projects i.e. loss of interest by stakeholder, blacklisted by authorities, waste of materialistic and time and damage of reputation.

\subsection{External related delay factors}

Several studies have identified external related delay factors category as one of the groups that causes of completion delays in construction projects. According to (6), observed that price accumulates unpredictable weather, labour strikes, government law, and late permit by government, civil disturbances and acts of god consecutively were critical. In another study, delay in obtaining work permits from authorities was ranked as the most significant cause of delay. According to (7) identified unfavourable weather conditions as the major cause of external related delays. According to (2) identified that the external related delay factors as effects of subsurface conditions such as high water table, soil, etc. For instance, delay in obtaining permits from municipality, hot weather that effect on construction activities, rain effect on construction activities, lack in availability of utilities in site such as, water, electricity, telephone, etc., effect of cultural and social factors, traffic control and prohibition at job site, accident cases during construction, inconsistent site (ground) conditions, changes in government regulations and laws, delay delivery of service in utilities such as water, electricity and, delay in performing final inspection and certify by a third party. According to (2), also identified the legal disputes, ineffective delay penalties lack of building materials in market, and delay in manufacturing special building materials as factors that contributed to delays.

\subsection{Business Process}

Figure 2.1 shows the structure flow of business process on each activity to be implied in simulation process for uncertainty module with their condition and solution. It is structured through pipeline construction of water supply company in Malaysia. The flows of process were developed according to late delivery project as provided.

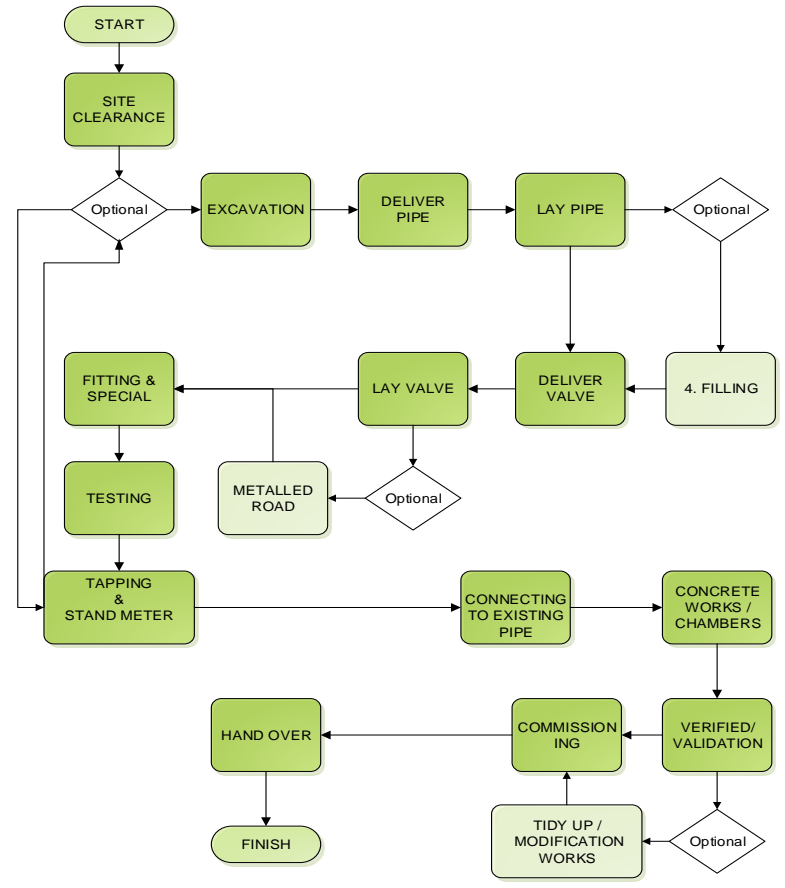

Fig 2.1: Piping process in piping construction

\section{Research Methodology}

\subsection{Introduction}

This chapter discussed about the research on the process and research methodology along the on-going project. Research methodology will explain the resources for data collection, the data collection activity was conducted and analysed. The methodology was used in this research was based on the previous research experts such as $(8-10)$.

\subsection{Data collection}

The data collection is an important element in the research operation. When the data collection was conducted, the company will be standing in a safe position. This is because the collected data is useful for their following activities. Without a complete data, the research will be limited. The data obtained from Gunung Ara Sdn Bhd executive officer, Mr Mazlan bin Abu Bakar (refer to appendix A) provided the business process according to the SAJ Sdn Bhd piping project process flow and the historical data of the uncertainty factors delay percentage as shown in Table 4.5 .The usage of observation method involved site viewing and documents refer based as collection the additional data from the Gunung Ara Sdn Bhd. 


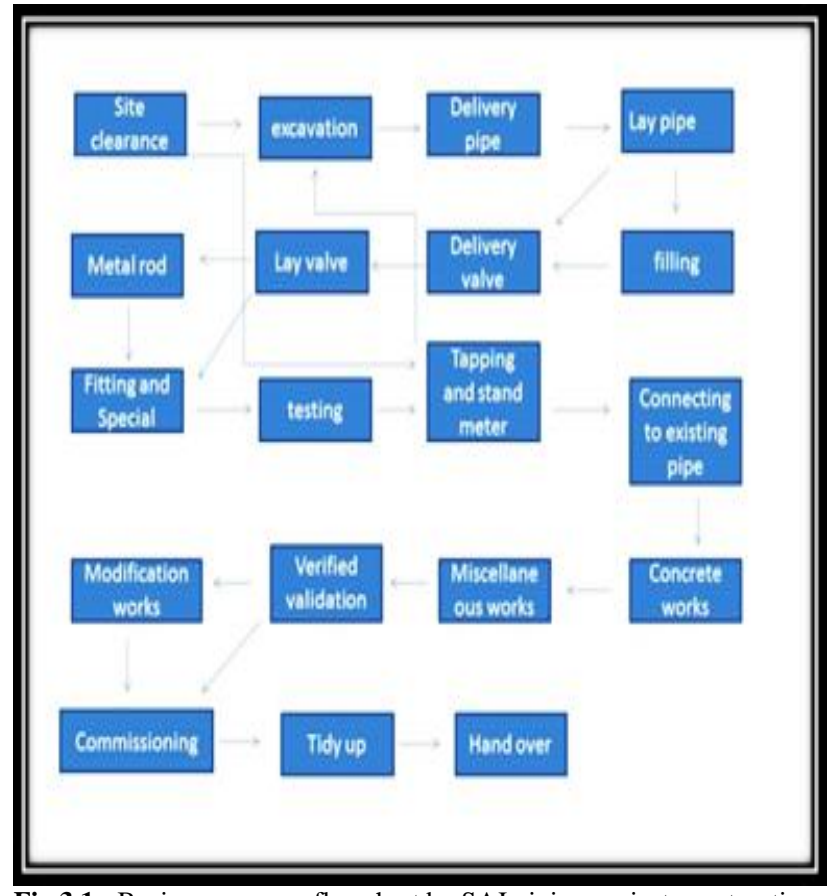

Fig 3.1: Business process flowchart by SAJ piping project construction

\section{Validate and Analysis}

In this section, the researcher attached the result as evidence. The researcher conducted the research and the data collected at SAJ Piping Project at Pontian, Johor. All the data was collected from the Gunung Ara SDN BHD as contractor of the project and analysed by using simulation software in order to get the end results and findings that act as evidence of the delay in the project. However, to test the system, the researcher will convert the data into simulation model.

\subsection{Data Input.}

Data input means the information, instruction and data collected from Gunung Ara Sdn Bhd contractor and used into simulation system. The input data for the research is represented in Table 4.3. The data resource was purposely constructed to key in the data processes in the simulation system. The table will help the researcher in inclusion of the data perfectly without any disturbance.

Table 4.3: Data resources for simulation system

\begin{tabular}{|c|c|c|c|c|}
\hline Process & Status & Mode & time shift & Activity \\
\hline $\begin{array}{c}\text { Site Clearance } \\
\text { (SC) }\end{array}$ & Major & Assemble & Shift 1 & Push \\
\hline Excavation (EXC) & Major & Assemble & Shift 1 & Push \\
\hline $\begin{array}{c}\text { Delivery pipes } \\
\text { (DP) }\end{array}$ & Major & Single & Shift 1 & Push \\
\hline Lay pipe (LP) & Major & Single & Shift 1 & Push \\
\hline
\end{tabular}

\begin{tabular}{|c|c|c|c|c|}
\hline $\begin{array}{l}\text { Delivery valve } \\
\text { (DV) }\end{array}$ & Major & Assemble & Shift 1 & Push \\
\hline Lay valve (LV) & Major & Assemble & Shift 1 & Push \\
\hline $\begin{array}{l}\text { Fitting and special } \\
(\mathrm{F \& S})\end{array}$ & Major & Single & Shift 1 & Push \\
\hline Testing (T) & Major & Single & Shift 1 & Push \\
\hline $\begin{array}{l}\text { Tapping \& stand } \\
\text { meter (T\&MS) }\end{array}$ & Major & Assemble & Shift 1 & Push \\
\hline $\begin{array}{c}\text { Connecting to } \\
\text { existing pipe }(\mathrm{CN})\end{array}$ & Major & Single & Shift 1 & Push \\
\hline $\begin{array}{c}\text { Concrete works } \\
(\mathrm{CW})\end{array}$ & Major & Single & Shift 1 & Push \\
\hline $\begin{array}{c}\text { Miscellaneous } \\
\text { works (MW) }\end{array}$ & Major & Single & Shift 1 & Push \\
\hline $\begin{array}{c}\text { Verified and } \\
\text { Validation (VV) }\end{array}$ & Major & Assemble & Shift 1 & Push \\
\hline $\begin{array}{c}\text { Commissioning } \\
(\mathrm{COMM})\end{array}$ & Major & Single & Shift 1 & Push \\
\hline Tidy up (TU) & Major & Single & Shift 1 & Push \\
\hline Hand over (HO) & Major & Single & Shift 1 & Push \\
\hline Filling $(F)$ & Optional & Single & Shift 1 & Push \\
\hline $\begin{array}{l}\text { Metalled road } \\
\text { (MR) }\end{array}$ & Optional & Single & Shift 1 & Push \\
\hline $\begin{array}{l}\text { Modification works } \\
\text { (MODW) }\end{array}$ & Optional & Single & Shift 1 & Push \\
\hline
\end{tabular}

The data resource is stated clearly by each column and row. The process defines each of the projects in the piping sector. The status differs between major process and optional process. The optional process indicates whether the process might be going through them when needed. The mode indicates configuration of the entities or the process that determines the total input and assign. The time shift means every each project will progress until eight hours only for a day. The time shift will be explained in detail on Table 4.4. Finally, the activities of each process consists only two variables such as push and pull. The activities determine the direction of the process in the simulation system.

Table 4.4: Multiple time shift

\begin{tabular}{|c|c|c|c|}
\hline Time shift & Hour & minutes & \% \\
\hline Shift 1 & 8 & 480 & 0 \\
\hline Shift 2 & 4 & 240 & 50 \\
\hline Shift 3 & 2 & 120 & 25 \\
\hline shift 4 & 1.3 & 80 & 10 \\
\hline Shift 5 & 0.67 & 40 & 5 \\
\hline
\end{tabular}

Table 4.4 shows the multiple time shifts have been created in the simulation system. The purpose for various time shift creation for assigning the uncertainty factors according to the data that will provide below. The shift created specifically between process and uncertainty factors involvement percentage. The minutes are conversion of the hours as shown below. For example, the factors only contribute about $50 \%$ of the process. This means, from eight hour of the working time, the particular factor will disturb only four hour. All involvement percentage factors will be provided in Table

below.

Table 4.5: The historical data of the factor delay percentage

\begin{tabular}{|c|c|c|c|c|c|c|c|c|c|c|c|c|c|c|}
\hline & \multicolumn{14}{|c|}{ ?ROJECT CONSTRUCTION ACTIVITIES } \\
\hline & SC & $\mathrm{EC}$ & PP/LP & $\mathrm{F}$ & $\mathrm{V} / \mathrm{LV}$ & MR & $\& S$ & ES & $\& M S$ & $\mathrm{CON}$ & EW & VV & OMM & $\mathrm{U} / \mathrm{HO}$ \\
\hline actors of uncertainty & 1 & 2 & 3 & 4 & 5 & 6 & 7 & 8 & 9 & 10 & 11 & 12 & 13 & 14 \\
\hline IAM RAIN & 50 & 50 & 50 & 50 & 50 & 50 & 50 & 0 & 50 & 50 & 50 & 50 & 100 & 0.5 \\
\hline H RAIN & 0 & 0 & 0 & 0 & 0 & 0 & 0 & 0 & 25 & 20 & 0 & 0 & 0 & 0 \\
\hline PH RAIN & 0 & 0 & 0 & 0 & 0 & 0 & 0 & 5 & 10 & 5 & 0 & 5 & 5 & 25 \\
\hline DRY & 0 & 0 & 0 & 0 & 0 & 0 & 0 & 0 & 0 & 0 & 0 & 0 & 0 & 0 \\
\hline FLOOD1 & 0 & 0 & 0 & 0 & 0 & 0 & 0 & 5 & 10 & 5 & 0 & 5 & 5 & 25 \\
\hline GOD & 0 & 0 & 0 & 0 & 0 & 0 & 0 & 0 & 0 & 0 & 0 & 0 & 0 & 0 \\
\hline SOIL1 & 0 & 0 & 0 & 0 & 0 & 0 & 0 & 5 & 0 & 0 & 0 & 0 & 0 & 0 \\
\hline SOIL2 & 50 & 20 & 0 & 0 & 0 & 0 & 0 & 0 & 0 & 0 & 50 & 0 & 25 & 100 \\
\hline SKILL & 0 & 0 & 0 & 0 & 0 & 0 & 0 & 5 & 10 & 5 & 0 & 5 & 5 & 25 \\
\hline UTILITY & 20 & 25 & 25 & 25 & 25 & 25 & 25 & 0 & 25 & 25 & 25 & 0 & 0 & 0 \\
\hline NEG & 0 & 0 & 0 & 0 & 0 & 0 & 0 & 5 & 50 & 5 & 0 & 5 & 5 & 25 \\
\hline
\end{tabular}


Table 4.5 shows the data of the uncertainty factors that will affect in terms of process in the business entities. Each of the factors contributes certain percentage on the process. The table is constructed by matrix method in relation to the two variables in percentage mode. For example, the IAM rain majorly contributes about $50 \%$ delays factors in the process. This means out of 8 hour working time, the factor affects about 4 hours in working time. Instead, the witness simulation system unable to absorb the data completely because of the limitation of the software. The data was chosen averagely to assign the factors by the percentage. The reduced table was shown as following.

Table 4.6 shows the factors that have been assigned to their time shift was created based on the delay percentage. The uncertainty factors need to be double clicked, choose the time shift available column and select the time shift according to the table above in the simulation system. This ensures all factors to be updates and functioning according to the settings. All factors has different time shift as assigned.

Table 4.6: The assigned time shift based on the delay percentage

\begin{tabular}{|c|c|c|}
\hline Uncertainty factors & Average delay (\%) & time shift \\
\hline IAM RAIN & 50 & shift2 \\
\hline H RAIN & 25 & shift3 \\
\hline PH RAIN & 10 & shift4 \\
\hline DRY & 0 & shift1 \\
\hline FLOOD1 & 25 & shift3 \\
\hline GOD & 0 & shift1 \\
\hline SOIL1 & 5 & shift5 \\
\hline SOIL2 & 50 & shift2 \\
\hline SKILL & 25 & shift3 \\
\hline UTILITY & 10 & shift4 \\
\hline NGE & 5 & shift5 \\
\hline
\end{tabular}

\subsection{The statistics of the uncertainty factors}

Table 4.7 shows the summary of the all 5 replica results which have been consolidated to analyse the trend of the data that was simulated. Each factor appears in the same percentage and more less a few differences for each another simulation result. All the data will be used to analyse the significance of each uncertainty factor towards the project.

\begin{tabular}{|c|c|c|c|c|c|c|}
\hline Type & Code & Result 1 & $\begin{array}{c}\text { Resul } \\
\mathrm{t} 2\end{array}$ & $\begin{array}{c}\text { Resu } \\
\text { It } 3\end{array}$ & $\begin{array}{c}\text { Resu } \\
\text { lt } 4\end{array}$ & $\begin{array}{c}\text { Resu } \\
\text { It } 5\end{array}$ \\
\hline $\begin{array}{c}\text { Intermittent } \\
\text { on AM }\end{array}$ & $\begin{array}{l}\text { IAM } \\
\text { RAIN }\end{array}$ & 35.40 & 34.40 & 34.00 & 33.85 & 33.82 \\
\hline Heavy & $\begin{array}{c}\mathrm{H} \\
\text { RAIN }\end{array}$ & 67.60 & 67.20 & 67.00 & 66.95 & 66.91 \\
\hline $\begin{array}{c}\text { Pouring } \\
\text { and heavy }\end{array}$ & $\begin{array}{c}\text { PH } \\
\text { RAIN }\end{array}$ & 67.40 & 67.00 & 66.87 & 66.85 & 66.82 \\
\hline Red & $\begin{array}{l}\text { FLO } \\
\text { OD } 1\end{array}$ & 34.60 & 35.30 & 45.73 & 50.95 & 52.41 \\
\hline Sweltering & DRY & 51.40 & 58.90 & 61.40 & 62.65 & 63.05 \\
\hline No & GOD & 99.00 & 99.50 & 99.67 & 99.75 & 99.77 \\
\hline Acidic & $\begin{array}{c}\text { SOIL } \\
1\end{array}$ & 34.00 & 33.70 & 33.53 & 33.50 & 33.50 \\
\hline $\begin{array}{c}\text { Soil } \\
\text { erosion }\end{array}$ & $\begin{array}{c}\text { SOIL } \\
2\end{array}$ & 33.40 & 33.40 & 33.40 & 33.40 & 33.36 \\
\hline $\begin{array}{c}\text { Cannot } \\
\text { Deflected }\end{array}$ & $\begin{array}{l}\text { UTIL } \\
\text { ITY }\end{array}$ & 33.00 & 33.30 & 33.33 & 33.35 & 33.32 \\
\hline Very poor & $\begin{array}{c}\text { SKIL } \\
\text { L }\end{array}$ & 33.40 & 33.40 & 33.40 & 33.40 & 33.36 \\
\hline $\begin{array}{c}\text { Workers- } \\
\text { Died }\end{array}$ & NEG & 33.00 & 33.20 & 33.27 & 33.30 & 33.27 \\
\hline
\end{tabular}

\section{Analysis of the results}

The result of the simulation data was keyed inside the SPSS software system as shown in appendix $\mathrm{O}$ until $\mathrm{T}$ to identify the significance of the uncertainty factors towards the project late completion. The result of significance was shown at Table 4.8 below,

Table 4.8: The uncertainty factors significant analysis using SPSS system

\begin{tabular}{|l|c|l|l|l|}
\hline \multicolumn{1}{|c|}{ Factors } & T & Df & Sig. Level & Mean difference \\
\hline IAM RAIN & 116.177 & 4 & 0.000 & 34.294 \\
\hline H RAIN & 527.863 & 4 & 0.000 & 67.132 \\
\hline PH RAIN & 623.205 & 4 & 0.000 & 66.988 \\
\hline FLOOD 1 & 11.5850 & 4 & 0.000 & 43.798 \\
\hline DRY & 27.7170 & 4 & 0.000 & 59.480 \\
\hline GOD & 697.692 & 4 & 0.000 & 99.538 \\
\hline SOIL 1 & 350.479 & 4 & 0.000 & 33.646 \\
\hline SOIL 2 & 4174.00 & 4 & 0.000 & 33.392 \\
\hline UTILITY & 507.801 & 4 & 0.000 & 33.260 \\
\hline SKILL & 4174.00 & 4 & 0.000 & 33.392 \\
\hline NEG & 608.937 & 4 & 0.000 & 33.208 \\
\hline
\end{tabular}

The main objective of the research was to design and develop the simulation model for piping construction activity. This was completed by using the Witness 2008 Manufacturing Edition. With the simulation tool, it is considered as a detection method in prevention of late completion of the project and achieved within the time period that has been announced.

\section{Conclusion and Recommendation}

Researcher establishing the research objectives. The first objective to determine the uncertainty environmental factors in the project delay completion. The second objective to design the simulation model inside the simulation environment using the Witness software system and final objective is to simulate the model and analyse the data. Research questions which were prepared are basically on the factors that cause the late completion project and uncertainties of late completion project. From the research question, the researcher has developed the initial model of piping construction process. Then, the results of the simulation design in the Witness. From the results as discussed the researcher has concluded the objectives are achieved.

\subsection{Recommendations based on findings}

The findings show it is possible to solve the issue by using the simulation model to prevent the late completion project. This research only focus on the late completion project of all uncertainties based of the environmental issues. Besides these issues, there are few more factors which lead to the late project completion such as delay in payment, unknown soil condition and accidents while constructions. For the future research, it is recommended to develop the simulation model based on these factors by using the Witness software system.

\section{References}

[1] Qureshi MI, Bashir N, Zaman K, Sajjad N, Fakhr S. Customer Satisfaction Measurement and Analysis using six sigma in Telecom sector of Pakistan. European Journal of Sustainable Development. 2012;1(1):53.

[2] Assaf SA, Al-Hejji S. Causes of delay in large construction projects. International journal of project management. 2006;24(4):349-57.

[3] Saleh A, Abdelnaser O, Abdul H, editors. Causes of delay in construction industry in Libya. The International Conference on Economics and Administration, Faculty of Administration and Business, University of Bucharest, Romania: ICEA-FAA Bucharest; 2009. 
[4] Assaf SA, Al-Khalil M, Al-Hazmi M. Causes of delay in large building construction projects. Journal of management in engineering. 1995;11(2):45-50.

[5] Wei KS. Causes, effects and methods of minimizing delays in construction projects. A project report. 2010

[6] Aibinu AA, Odeyinka HA. Construction delays and their causative factors in Nigeria. Journal of construction engineering and management. 2006;132(7):667-77.

[7] Arditi D, Akan GT, Gurdamar S. Reasons for delays in public projects in Turkey. Construction management and economics. $1985 ; 3(2): 171-81$
[8] Chan DW, Kumaraswamy MM. A comparative study of causes of time overruns in Hong Kong construction projects. International Journal of project management. 1997;15(1):55-63.

[9] Kumaraswamy MM, Chan DW. Contributors to construction delays. Construction Management \& Economics. 1998;16(1):17-29.

[10] Ling FYY, Hoi L. Risks faced by Singapore firms when undertaking construction projects in India. International Journal of Project Management. 2006;24(3):261-70. 